\title{
THE INHIBITION OF FROSTBITE WHEALS BY THE IONTOPHORESIS OF ANTIHISTAMINIC AGENTS ${ }^{1}$
}

\author{
By MARTIN B. MACHT, ${ }^{2}$ MORTIMER E. BADER, ${ }^{3}$ AND JERE MEAD ${ }^{3}$ \\ With the techNical assistance of ELIZABETH L. PILLION
}

(From the U.S. Army, Quartermaster Climatic Research Laboratory, Lazirence, Mass.)

(Received for publication December 17, 1948)

Skin whealing associated with localized frostbite is a well recognized phenomenon and has been described in detail by Lewis and his co-workers $(1,2)$. Although no positive evidence of histamine liberation in frostbite has been advanced, it has been postulated that histamine or a histaminelike substance is involved in the formation of these lesions (2). Recently. Frommel and Picquet have reported beneficial results from the antihistaminic drug, dimethylaminoethyl-ethylbenzylaniline hydrochloride (Antergan), in the treatment of frostbite in guinea pigs (3).

The inhibition of histamine wheals by the oral or intradermal administration of beta-dimethylaminoethyl benzhydryl ether (Benadryl, Parke-Davis) and N'pyridil-N'benzyl-N'dimethylethylenediamine hydrochloride (Pyribenzamine, Ciba) has been demonstrated conclusively (4-6). A similar inhibition can be achieved locally by the iontophoresis of Pyribenzamine (7).

In an effort to gain additional information regarding the role of histamine in the pathogenesis of local frostbite, we have studied experimentally produced frostbite lesions before and after the iontophoretic administration of Benadryl and Pyrilenzamine. The results obtained are presented in this paper.

\section{METHODS}

Twelve healthy young males were used as subjects. The ventral surfaces of the forearms and/or thighs were shaved. By means of an ordinary iontophoresis apparatus, various test solutions were introduced into rectangular areas of skin measuring $5 \times 5 \mathrm{~cm}$. The positive electrode

1 This work has been performed in collaboration with the Medical Department, United States Army, which has assigned Medical Corps Officers to the Quartermaster Climatic Research Laboratory for research on adaptations of man to environmental stresses.

2 Formerly Captain, Medical Corps, AUS. Present address: Jewish Hospital, Cincinnati, Ohio.

${ }^{3}$ Captain, Medical Corps, AUS. was constructed of copper screening covered with flannel. The flannel was saturated with the solution to be tested and was secured firmly to the skin by means of a canvas strap. A current density of 0.5 milliamperes per sq. $\mathrm{cm}$. was applied for four minutes in each case. The solutions introduced by electrophoretic means were (1) $0.9 \%$ $\mathrm{NaCl}$, (2) a saturated solution of Pyribenzamine hydrochloride, and (3) a saturated solution of Benadryl hydrochloride. Since each subject acted as his own control, the various solutions were usually applied to the same extremity in rectangular areas one inch apart. In those cases in which sufficient surface area was not available, Pyribenzamine and a saline control were placed on the skin of one extremity, while Benadryl and a saline control were applied in a similar manner to the skin of the opposite extremity. After one hour the erythema which routinely followed the iontophoresis of any of the solutions had usually disappeared. Localized frostbite was then produced by means of a jet of cold air directed at the skin. The air was first dried and was then passed through coils of copper tubing embedded in an insulated cask of dry ice. The rate of flow was measured by means of a standard gasometer placed in the system, and the temperature of the air was determined by means of a thermocouple placed at the end of a 16-inch length of $3 / 8$-inch rubber tubing which served as the outlet. A1though the intensity and duration of the stimulus varied somewhat from subject to subject, the same stimulus was always applied to the areas tested on any particular subject during a single experiment. It was found that a jet of air at a temperature of $-40^{\circ} \mathrm{F}$. applied for ten seconds resulted in satisfactory and reproducible lesions. In a single experiment the same cold stimulus was applied to each of the treated areas and to one untreated area nearby. Observations were made of the time of onset, degree and size of wheal formation.

\section{RESULTS}

During, and for a short time following, the iontophoresis of any of the substances used, the subjects reported slight discomfort, usually described as "burning or tingling" at the site of application. This discomfort was equally great whether saline, Benadryl, or Pyribenzamine was used. Similarly, no differences between the saline control and the anti-histaminic agents were noted with regard to local erythema or papule formation. 
The time required for freezing the treated and the untreated areas did not vary significantly. Onset of freezing was heralded by a pricking or burning sensation and blanching of the skin. Within a few seconds, frost began to accumulate on the frozen skin and after ten seconds or more (depending on the intensity of the stimulus), a hard, frozen, cream-colored area, approximately $1.5 \mathrm{~cm}$. in diameter, could be picked up between the fingers. This thawed in a matter of $60 \mathrm{sec}-$ onds. Within a few minutes the frostbitten area became red and was sharply demarcated from the surrounding skin. In the untreated areas, a wheal invariably began to form within five minutes after removal of the stimulus, continued to swell until it reached a maximum in approximately 20 minutes, and gradually subsided in from one to four hours.

The wheals were graded I to III :

$$
\begin{aligned}
\mathrm{I} & =\text { Minimal or no wheal formation } \\
\text { II } & =\text { Slight to moderate wheal formation } \\
\text { III } & =\text { Marked wheal formation }
\end{aligned}
$$

The whealing was strikingly inhibited in the areas where the histamine antagonists had been introduced (Table I, Figure 1). Benadryl was slightly less effective than Pyribenzamine. Iontoproresis of normal saline had essentially no effect on wheal formation. When wheals did appear in the areas treated with the anti-histaminic agents, the time of appearance was invariably delayed. In most cases the duration and intensity of the cold stimulus were not sufficient to produce vesicle formation. In the few subjects in whom vesicles were produced they tended to be less severe in the areas treated with Benadryl or Pyribenzamine. In all instances the frostbitten skin was tender and

TABLE I

\begin{tabular}{|c|c|c|c|}
\hline \multirow{2}{*}{$\begin{array}{l}\text { Area } \\
\text { frostbitten }\end{array}$} & \multicolumn{3}{|c|}{$\begin{array}{l}\text { Number of subjects showing various degrees } \\
\text { of wheal formation }\end{array}$} \\
\hline & Grade I & Grade II & Grade III \\
\hline $\begin{array}{l}\text { Untreated } \\
\text { Saline }\end{array}$ & 0 & 1 & 11 \\
\hline $\begin{array}{l}\text { Iontophoresis } \\
\text { Benadryl }\end{array}$ & 0 & 2 & 10 \\
\hline Iontophoresis & 10 & 1 & 1 \\
\hline Iontophoresis & 11 & 1 & 0 \\
\hline
\end{tabular}

The effects of anihistaminic agents on frostbite wheals in twelve subjects

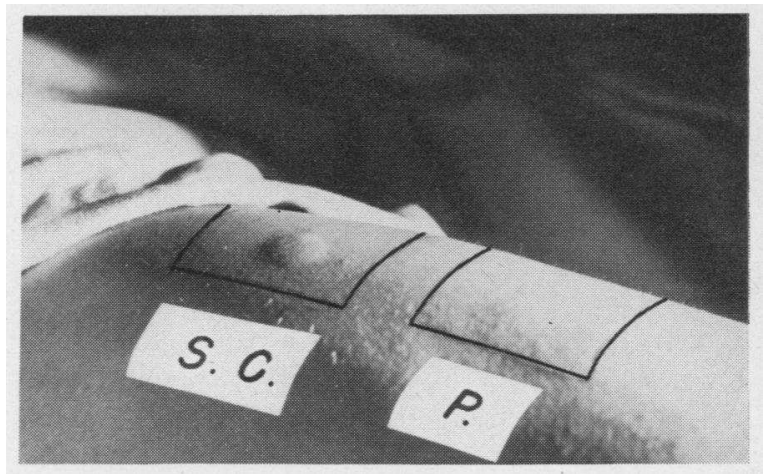

Fig. 1. The Inhibition of Frostbite Wheal on the Thigh by Previous Iontophoresis of PyribenzaMINE HydROCHLORIDE

S.C. = saline control, P. = pyribenzamine. Cold stimulus applied to both areas was jet of air at $-40^{\circ} \mathrm{F}$. for ten seconds.

somewhat painful for approximately 48 hours. The redness persisted for several days and was followed by scaling with eventual disappearance of the lesion in approximately three weeks. A comparison of the treated and untreated areas revealed no significant differences in the progress and ultimate outcome of the frostbite lesions.

\section{SUMMARY AND CONCLUSIONS}

1. Introduction of the histamine antagonists, Pyribenzamine hydrochloride and Benadryl hydrochloride, by an iontophoretic technique inhibited the formation of frostbite wheals in the human skin.

2. In these experiments no other effects of antihistamine agents on the type or progress of localized frostbite lesions were observed.

3 . It is concluded from these studies that histamine or a histamine-like substance is liberated in the human skin in the early stages of frostbite.

\section{BIBLIOGRAPHY}

1. Lewis, T., and Love, W. S., Vascular reactions of the skin to injury; effects of freezing, of cooling and of warming. Heart, 1926, 13, 27.

2. Lewis, T., The Blood Vessels of the Human Skin and Their Responses. Shaw \& Sons, London, 1927.

3. Frommel, E., and Picquet, J., La thérapeutique des gelures peut-elle nous donner la clef d'une pathogénie? Traitement à la belladone (antiacétylcholinique) au chlorhydrate de diméthylaminoéthyl-éthylbenzylaniline (antihistaminique), au chlorhydrate d'histidine (antiacétylcholinique et antihistaminique) et à l'association de l'atropine et 
du chlorhydrate đe diméthylaminoéthyl-éthylbenzylaniline. Arch. internat. de pharmacodyn. et de thérap., 1946, 73, 96.

4. Friedlander, S., and Feinberg, S. J., Histamine antagonists; effect of oral and local use of $\beta$-dimethylaminoethyl benzhydryl ether hydrochloride on whealing due to histamine, antigen-antibody reactions, and other whealing mechanisms; therapeutic results in allergic manifestations. J. Allergy, 1946, 17, 129.

5. Arbesman, C. E., Kopf, G. F., and Miller, G. E., Some antianaphylactic and antihistaminic proper- ties of N'pyridyl, N'benzyl, dimethyl-ethylenediamine monohydrochloride (pyribenzamine). J. Allergy, 1946, 17, 203.

6. Cohen, M. B., Friedman, H. J., Zonis, J., Burke, M., and Abram, L. E., The effect of beta-dimethylaminoethyl-benzhydryl-ether-hydrochloride on the histamine threshold of human skin. J. Allergy, 1947, 18, 32.

7. Aaron, T. H., and Abramson, H. A., Inhibition of histamine whealing in human skin by pyribenzamine hydrochloride using iontophoretic techniques. Proc. Soc. Exper. Biol. \& Med., 1947, 65, 272. 